Original Research Paper

\title{
Role of Web Usability in Online Customer Experience: A Case of Saudi Arabia
}

\author{
Saqib Saeed \\ Department of Computer Information Systems, College of Computer Science and Information Technology, \\ Imam Abdulrahman Bin Faisal University, P.O. Box 1982, Dammam, Saudi Arabia
}

Article history

Received: 13-03-2019

Revised: 14-04-2019

Accepted: 30-05-2019

Email: saqib.saeed@gmail.com

\section{Introduction}

Digital technologies have radically transformed the conventional business resulting in global reach to customers, innovative business models and robust communication approaches. As a result, organizations need to carry out significant changes in their organizational processes to optimally benefit from the advantages of the electronic business. Electronic commerce can be grouped into Business to Business (B2B), business to consumer (B2C), Consumer to Consumer (C2C), Consumer to Business (C2B), Employee to Employee (E2E), Government to Consumer (G2C), Government to Business (G2B), Consumer to Government (C2G), Business to Government (B2G) and Government to Government (G2G) (Chaffey, 2015).

The online marketplace is different from conventional market structure and has its own ecosystem. In an online marketplace, horizontal and vertical search engines, specialist directories, aggregators, affiliates, blogs and company websites have a huge influence on customers online shopping preferences. Furthermore, diverse customer segments provide a challenge for online businesses to develop online value proposition for their customers. In order to be successful in online business, merely providing an online portal does not warrant a success. A successful ebusiness operation requires well thought out strategy, digital business infrastructure management, digital marketing, esupply chain management, e-procurement and e-customer relationship management practices in place. The businesses also need to rely heavily on (re) intermediation, counter mediation and even disintermediation to gain a competitive advantage in the online marketplace (Chaffey, 2015). In this research, we are primarily focusing on the role of usability of company websites to foster customer satisfaction in the e-business. Usability is defined as the ease in using of a software application to achieve its intended objective with effectiveness, efficiency and user satisfaction (Nielsen, 1999). If an e-business website is not usable, it will neither be able to convert offline customers to online customers nor retain the existing online 
customers and will not be even helpful in providing supporting information for offline customers.

In this paper, we explore the usability implications for e-business applications in Saudi Arabia. Saudi Arabia is an emerging market for e-business and according to the United Nations Conference on Trade and Development Saudi Arabia is ranked at B2C e-business index on 46th position globally (UNCTAD B2C E-COMMERCE INDEX, 2017). According to a recent survey, conducted by Communication and Information Technology Commission of Saudi Arabia, 58\% of Saudi residents have done online shopping at least once (SANB, 2018). It is estimated that online shopping will rise to 13.9 Billion $\$$ by 2021 in Saudi Arabia (ECSA, 2018). So, this makes the Kingdom of Saudi Arabia an interesting case to explore the usability aspects of different e-business applications to measure user experience.

Rest of the paper is structured as follows. Section 2 discusses the related work, followed by the research problem and methodology in section 3 . Section 4 presents findings of the study, section 5 documents discussion followed by conclusion in section 6 .

\section{Related Work}

Like any other software application, usability is also an important characteristic of a website to foster successful usage by end users. There have been many studies looking the usability of web-based applications in different information systems environments such as busines (Saeed and Amjad, 2013; Saeed et al., 2012), health (Brown and Kim, 2018; Chin et al., 2018; Gerber et al., 2018), education (Solomon, 2017; Heiman et al., 2017) government (Saeed et al., 2013) and nonprofit organizations (Saeed and Shabbir, 2014). Despite these studies, every instance of a software artifact is unique due to the associated sociotechnical process focusing on the diversity of user behaviors, cultures, skills, organizational policies and nature of technical artifacts.

Usability has a greater role in the acceptance of online marketplace. Saeed et al. (2013) have looked at the usability aspects of Pakistani E-Government and ebusiness websites and concluded that there are many usability issues associated with these websites. Bart et al. (2005) have devised different drivers of trust for customer retention and usability of the website is one of them. They highlighted that better accessibility and usability can improve the user experience and could turn out to be a deciding factor in customer retention. Kim and Lee (2006) analyzed American and Korean online buyers and found that there is a direct relationship among the quality of the website and users' intention to make purchase decision. Nantel and Glaser (2008) conducted a study in Canada with native English and French speakers and highlighted that there is a high chance that users will abandon an online shopping if the website is not available in their own language. They further describe that not only the quality of language translation is mandatory, but it is also important that the linguistic background of users and website designers should converge. Rehman (2016) carried out an empirical study at e-commerce websites in Pakistan and found that culture has an implication on the user's choice of an e-commerce website for shopping. Sfernrianto et al. (2018) has explored the Indonesian electronic marketplace and found that usability factors have an impact on the acceptance of e-services and that in turn affects the trust of potential buyers.

In the context of Saudi Arabia, Al-Ghamdi et al. (2012) have looked at the motivating factors for retailers to adopt e-commerce in Saudi Arabia and highlighted numerous cultural, business and technical issues to promote e-commerce. Abed et al. (2015) have carried out a systematic literature review of social media usage by retailers in Saudi Arabia and chalked out different knowledge gaps to carry out further research. Hidayat-urRehman et al. (2016) found that perceived usefulness, trust and satisfaction are critical factors for Saudi online buyers. Azyabi (2018) found that knowledge acquisition is the core knowledge management process impacting ebusiness, whereas knowledge dissemination and knowledge application have little role in the adoption of e-business by Saudi SMEs. Baabdullah et al. (2019) have highlighted different factors for fostering successful usage and customer loyalty of mobile banking. Alqahtani et al. (2018) conducted an empirical study to understand the impact of cultural variables on the adoption of e-commerce in Saudi Arabia. Saeed (2019a) has carried out an empirical study to understand the implications of e-commerce adoption among the expatriate community in Saudi Arabia.

Durucu et al. (2019) have analyzed the banking websites in Turkey and found that navigations and interaction related usability aspects are more important to banking customers than the functionality of the websites. Chong and Law (2018) carried out a rigorous literature review on airline website evaluation studies and found that the websites of airlines need major rework. Valenti (2018) carried out usability testing of a community college library website and found major issues on the website, which need to be fixed to make usage of users more convenient. Danielson et al. (2014) have carried out a usability testing of an HIV prevention website in Africa and found that users feel website helpful but there is need to fix some usability aspects such as navigation design. Pee et al. (2018) highlighted that website usability is an important factor in online customers repurchase decision. Fung et al. (2016) evaluated the mobile version of University of Hong Kong library and found many usability issues such as inconsistency in user interfaces, advanced features for expert users and unclear error messages. Ali (2017) has investigated the usability of hotel websites and found that hotel website quality contributes to user satisfaction and committing the purchase decision. Hasbullah et al. (2016) investigated the Malaysian youth intention to buy using websites and found that usability of the website plays a significant role in the intention to purchase. 
Despite these studies in different geographical contexts, the results of these user studies cannot be directly generalized because of variations of involved, users, involved websites and application domain. There is not much work measuring the usability effectiveness of different business websites in Saudi Arabia. Such a study will provide a benchmark about the design strengths and limitations of Saudi e-business portals and provide guidelines for prospective online retailers to take benefit from these guidelines. Keeping this in view, in this paper we are focusing to evaluate the usability of business portals operating in Saudi Arabia.

\section{Research Question and Methodology}

In our current study, our focus was on understanding that whether e-business websites in Saudi Arabia are designed to have positive online customer experience and are there any special design issues which are negatively affecting the end users. In order to get the empirical data for our research question, we carried out a cross-sectional study. We designed an evaluation experiment for a group of students who were trained in user interface evaluation. We grouped the users into two cohorts. In group 1, there were 26 participants and in the second group there were 39 participants. We selected a total of 8 business websites to have a user interface evaluation which were grouped into retailers and booking websites. The selection was based on their popularity among users. During the experiment, each user interacted with respective websites for 30 minutes and at the end, they were asked to fill an online questionnaire. The questions in the questionnaire were decomposed in three categories namely navigation, design and content. The questionnaire was reused from an earlier work, where this questionnaire was used to evaluate the usability of nonprofit organizations (Saeed, 2019b). The questionnaire was based on important usability aspects highlighted in usability literature (https://garyperlman.com/quest/) and was already tested for content validity. Each question in the questionnaire had a Likert scale from 1-5, 1 being the minimum and 5 being the maximum (there were few questions where minimum and maximum values were other way round). Later, the data was analyzed in Microsoft Excel to extract the findings.

\section{Findings}

Since the evaluators were categorized into two groups so the findings are discussed for both groups. The first group was mainly looking at 4 retail e-business website namely Namshi.com, Souq.com, Wadi.com and Xcite.com whereas the second group was mainly looking at reservation websites. It included Agoda.com, Booking.com, Hotels.com and Altayyargroup.com. In order to acquire quantitative data, a questionnaire was used as a research method. In the first section of the questionnaire, we mainly focused on the questions related to the navigational aspects of the websites. Navigational ease is one of the main factors in the accessibility of any web application. In our questionnaire, 9 questions focused on this aspect. Questions asked respondents about their feedback on links intended functionality, appropriateness of external links, the presence of misleading links and orphan pages, Sitemap navigability and navigational escape to home page and navigation within the page. The results of these questions are discussed in Table 1. If we look at group 1, the mean values for question 5 and 6 were estimated to be nearing the minimum but we can see they are 2.00 and 1.88 respectively which means users found some links where menu items disappeared and some orphan pages on the websites. Similarly, navigation within the webpage and links to sitemap were the factors which scored less, highlighting that users want better navigation within a website and across pages so that they do not get lost while browsing on the website. In the case of group 2, the average ratings about the correctness of sitemap, links and navigation within the page appear marginally better than group 1, but overall, they are aligned with the results of group 1 .

Table 1: Ratings for navigation related questions

\begin{tabular}{|c|c|c|c|c|}
\hline & \multicolumn{2}{|c|}{ Group $1(\mathrm{~N}=26)$} & \multicolumn{2}{|c|}{ Group $2(\mathrm{~N}=39)$} \\
\hline & Mean & $\begin{array}{l}\text { Standard } \\
\text { Deviation }\end{array}$ & Mean & $\begin{array}{l}\text { Standard } \\
\text { Deviation }\end{array}$ \\
\hline All links are working & 3.88 & 1.07 & 3.77 & 1.06 \\
\hline Links to outer pages are appropriate and reliable. & 4.19 & 0.94 & 4.28 & 0.86 \\
\hline All pages have navigational menu or link to other pages in the site. & 4.31 & 0.74 & 4.54 & 0.55 \\
\hline $\begin{array}{l}\text { There is no misleading links (the destination page which was } \\
\text { opened by the link was same as expected by the user). }\end{array}$ & 4.46 & 0.99 & 4.36 & 1.11 \\
\hline $\begin{array}{l}\text { Presence of links causing menu to disappear (there is any link } \\
\text { which when selected causing main link to disappear). }\end{array}$ & 2.00 & 1.26 & 2.0 & 1.41 \\
\hline $\begin{array}{l}\text { Presence of Orphan pages (the site has some dead-end pages, } \\
\text { that doesn't have link to any other page). }\end{array}$ & 1.88 & 1.11 & 1.64 & 0.99 \\
\hline Links to site map are correct. & 2.62 & 1.79 & 3.31 & 1.72 \\
\hline There is Navigation back to home page on every page. & 4.23 & 1.07 & 4.51 & 0.82 \\
\hline There is Navigation up and down within a page. & 2.96 & 1.75 & 3.31 & 1.61 \\
\hline
\end{tabular}


Table 2: Ratings for design related questions

\begin{tabular}{|c|c|c|c|c|}
\hline & \multicolumn{2}{|c|}{ Group $1(\mathrm{~N}=26)$} & \multicolumn{2}{|c|}{ Group $2(\mathrm{~N}=39)$} \\
\hline & Mean & $\begin{array}{l}\text { Standard } \\
\text { Deviation }\end{array}$ & Mean & $\begin{array}{l}\text { Standard } \\
\text { Deviation }\end{array}$ \\
\hline Internal search is effective. & 4.15 & 1.38 & 4.54 & 0.91 \\
\hline Inconsistency in the language of the interface (links at English & & & & \\
\hline interface open pages that displayed Arabic content and vice versa). & 1.92 & 1.29 & 1.97 & 1.35 \\
\hline Format is consistent throughout the site & 4.04 & 0.82 & 4.31 & 0.77 \\
\hline Figures and tables are aligned correctly & 4.62 & 0.50 & 4.62 & 0.54 \\
\hline Font Style is same throughout the website. & 4.19 & 0.75 & 4.23 & 0.93 \\
\hline Font Size is same throughout the website. & 3.85 & 0.92 & 3.54 & 1.27 \\
\hline Layout of the website is very simple. & 3.73 & 0.83 & 3.79 & 0.83 \\
\hline Are icons concrete and familiar? & 4.35 & 0.75 & 4.36 & 0.67 \\
\hline Are icons labelled? & 3.58 & 1.17 & 3.95 & 1.05 \\
\hline Consistent Colors throughout website? & 4.54 & 0.71 & 4.49 & 0.82 \\
\hline Menu design is consistent. & 4.19 & 0.98 & 4.33 & 0.74 \\
\hline Menus are highlighted when they are selected. & 3.88 & 1.45 & 3.82 & 1.59 \\
\hline Colors are used appropriately. & 4.31 & 0.74 & 4.31 & 0.89 \\
\hline The alignment of the header on each page is consistent. & 4.42 & 0.76 & 4.54 & 0.6 \\
\hline
\end{tabular}

Table 3: Ratings for content related questions

\begin{tabular}{|c|c|c|c|c|}
\hline & \multicolumn{2}{|c|}{ Group $1(\mathrm{~N}=26)$} & \multicolumn{2}{|c|}{ Group $2(\mathrm{~N}=39)$} \\
\hline & Mean & $\begin{array}{l}\text { Standard } \\
\text { Deviation }\end{array}$ & Mean & $\begin{array}{l}\text { Standard } \\
\text { Deviation }\end{array}$ \\
\hline All pages have proper headings. & 4.08 & 0.84 & 4.28 & 0.83 \\
\hline The quality of all images is good. & 4.50 & 0.76 & 4.54 & 0.72 \\
\hline Headings are user friendly and intuitive. & 4.46 & 0.58 & 4.44 & 0.68 \\
\hline Headings are task based. & 4.27 & 0.78 & 4.13 & 1.06 \\
\hline Text is simple, concise, and clear. & 4.23 & 0.65 & 4.28 & 0.72 \\
\hline Level of technical terms is appropriate to the audience. & 4.42 & 0.50 & 4.28 & 0.56 \\
\hline Foreign Language Support is available? & 4.15 & 1.29 & 4.08 & 1.20 \\
\hline Information is current? & 4.42 & 0.81 & 4.44 & 0.75 \\
\hline Information is complete (no missing information). & 4.19 & 0.75 & 4.10 & 0.75 \\
\hline $\begin{array}{l}\text { Presence of pages with empty content. (Is there any blank } \\
\text { page on the website without any information?) }\end{array}$ & 1.62 & 1.06 & 1.41 & 0.91 \\
\hline Are there any misspelling of words? & 1.69 & 0.97 & 1.67 & 1.06 \\
\hline Are there any grammatical error? & 1.85 & 0.92 & 1.56 & 0.75 \\
\hline Site has some punctuation errors? & 1.69 & 0.88 & 1.59 & 0.59 \\
\hline Entries are in alphabetical order. & 2.35 & 1.32 & 2.31 & 1.30 \\
\hline Headings within page are labelled correctly. & 4.12 & 0.71 & 4.21 & 0.83 \\
\hline At least one heading exists on every page. & 4.35 & 0.98 & 4.41 & 0.88 \\
\hline Headings accurately reflect task or information. & 4.38 & 0.50 & 4.46 & 0.64 \\
\hline Giving feedback and asking questions are facilitated. & 4.54 & 0.58 & 4.10 & 1.05 \\
\hline The site has simple domain name. & 4.73 & 0.60 & 4.59 & 0.72 \\
\hline Phone number, fax number, e-mail, and postal address are included on each page. & 3.23 & 1.37 & 3.23 & 1.40 \\
\hline Help facility is provided. & 4.15 & 1.35 & 4.31 & 1.10 \\
\hline Site map is included. & 2.27 & 1.71 & 2.69 & 1.75 \\
\hline The home page contains main category headings that are descriptive and short. & 4.38 & 0.94 & 4.49 & 0.85 \\
\hline A search tool is included on the site. & 4.54 & 1.21 & 4.90 & 0.38 \\
\hline A user can find an answer within 10 seconds. & 4.08 & 1.02 & 4.00 & 0.97 \\
\hline The date of the last updated is included at the bottom of every page. & 2.42 & 1.45 & 2.23 & 1.37 \\
\hline Purpose Statement is provided. & 3.73 & 1.15 & 3.64 & 1.14 \\
\hline
\end{tabular}

The second section of the questionnaire contained 14 questions focusing on the design of the website. If we look at the results of group 1, ideally question 2 should have a lower value whereas the rest of the questions should have a higher value. As per Table 2 font size consistency, layout simplicity, labelling of icons got average less than 4 , highlighting that there is a need to specifically focus on these aspects to better engage users on these e-business websites. In the case of group 2, ratings of design related questionnaires are also 
consistent with group 1, where question 6, 7, 9 and 12 have an average less than 4 . The third section of the questionnaire contained 27 questions and focused mainly on content related issues.

For an ideal website, questions 10-13 should have values leaning towards 1 whereas the rest of the answers should be approaching 5. It can be seen in Table 3 that ordering, the absence of contact information, sitemap and date of the last updating got poor average ratings from the users. In the case of group 2, as shown in Table 3, ordering contact information, the absence of sitemap and date of the last updating got weaker average ratings.

\section{Validity of Results}

In order to validate the findings, we carried out Anova and calculated the Cornbach Alpha values for both groups. For group 1 the value of Cornbach Alpha was 0.66 whereas Group 2 has the value of 0.79 . Which means that internal validity for group 1 is weaker as compared to group 2 but results of both groups converge.

\section{Discussion}

Online business is the enabler for many organizations but being successful in electronic marketplace business organizations need to carry out optimal technological interventions in their organizational settings. Saudi Arabia is an emerging online market and many companies are focusing on this market segment. There are some research contributions studying customer satisfaction and other trust factors. However, there was a knowledge gap that there was no specific study investigating the usability implications of business websites in Saudi Arabia.

Web navigation is critical in making a highly usable website, keeping in mind the users' cognitive load and disorientation ( $\mathrm{Xu}$ et al., 2001). In our findings, we can see that despite the different size in both groups the values are almost converging which means that both group websites were sharing almost the same strengths and weaknesses. Internal navigation is the most critical factor in terms of navigation which needs to be considered for our target web portals. Designing web user interfaces needs to consider, information seeking behavior of users, their work practices and cultural orientations to foster successful usage (Zaphiris and Kurniawan, 2007). In our study, we can identify that the language interoperability is reported as a major problem. The Arabic-English conversion among user interfaces was found to be inconsistent. Furthermore, the menu and layout design were the other important areas where users reported the need for improvement. Content is another important factor contributing to better usability of webpages. In our study we can see missing contact information, the absence of last update date were the obvious weak points. As a result, the user may doubt the authenticity and currency of information.

From the results, we can deduce that in order to improve customer engagement and retention, Saudi ebusiness portals need to improve the design of their web applications. In order to improve the web navigation, requirements need to be better understood and a critical cognitive evaluation of users and tasks can help to better understand the navigations requirements. Ethnographic studies of user behaviors and task analysis can prove very effective during this stage. In order to improve the design aspects of websites, designers can use participatory design methodologies to foster better user experience (Santa et al., 2018; Schuler and Namioka, 1993; Fleming and Koman, 1998). Saudi enterprises need to have an optimal strategy to develop IT infrastructures which are appropriate to the user needs. A poorly designed e-business portal discourages users to participate and can negatively affect the trust (Rehman, 2018; Sfernrianto et al., 2018). Recently there has been a growth in user-centered design discourse which focuses on user first approach towards system design. This design methodology can also be employed to improve the usability of e-business portals (Pipek and Wulf, 2009; Monk, 2000; Wulf et al., 2015). In the case of content, user analysis can help in understanding the content needs of the users and technical writers can be involved to provide error free content.

Our study had a limitation that it has a small sample size in terms of evaluators as well as representative websites being examined so our findings may not be generalizable, but it points better insights into the usability weaknesses. As a next step, a qualitative study can be designed to understand deeply the user feedback and fixing those design deficiencies and measuring the effectiveness of revised portals.

\section{Conclusion}

The online marketplace has transformed the conventional business processes. Although this has increased the global reach of the businesses, it has also increased the power of end users. Customers have now become proactive in information sharing and website is the key resources in establishing their purchase intent. Customer acquisition and customer retention strategies focus on the provision of quality service to customers. In order to be successful in digital business, technological infrastructure needs to be appropriated for the needs of different customer segments. This is a very challenging task and requires a well thought out strategy, execution and management. User interface design is one of the core dimensions of usable e-business applications and organizations need to give special attention to improve the usability of their e-business portals. 
In this research, we have carried out an exploratory study to understand the usability applications of different e-business portals in Saudi Arabia. Saudi Arabia is an emerging market for online business and companies are focusing on this important geographical region to enhance online revenue contribution. Our qualitative study took a cross-sectional view of users, regarding the usability aspect of different online portals. Our survey was divided into 3 subsections focusing on navigation, design and content related questions. It was interesting to observe that in the majority of the questions' respondents gave positive ratings, however, there are some usability problems with these websites, and which may have a negative impact on user engagement with these portals. There is a need by the designers of these portals to specifically look at internal navigation within a page, inconsistency in language interfaces, website layout, labeling of icons, missing contact information and last update date to give users more user satisfaction to the customers. The improvements in these aspects will help in attracting more customers to these portals and ultimately increase the business revenue by better customer acquisition, extension and retention. There is a need for long term studies to quantitatively measure the impact of improved usability on customer behavior.

\section{Acknowledgement}

Author would like to thank Mr. Sardar Zafar Iqbal and Mrs. Hina Gull for their help in data collection.

\section{Ethics}

The data was collected using the anonymous survey to conceal the identity of the respondents.

\section{References}

Al-Ghamdi, R., S. Drew and W. Al-Ghaith, 2012. Factors influencing e-commerce adoption by retailers in saudiarabia: A qualitative analysis. Electronic J. Inform. Syst. Developing Countries, 47: 1-23. DOI: 10.1002/j.1681-4835. 2011.tb00335.x

Abed, S.S., Y.K Dwivedi and M.D. Williams, 2015. SMEs' adoption of e-commerce using social media in a Saudi Arabian context: A systematic literature review. Int. J. Business Information Systems, 19: 159-79. DOI: 10.1504/IJBIS.2015.069429

Ali, F., 2017.Hotel website quality, perceived flow, customer satisfaction and purchase intention. J. Hospitality Tourism Technol., 72: 13-228. DOI: $10.21512 /$ bbr.v8i1.1680

Alqahtani, A.S., R.D. Goodwin and D.B. de Vries, 2018. Cultural factors influencing e-commerce usability in Saudi Arabia: Int. J. Adv. Applied Sci., 5: 1-10. DOI: 10.21833/ijaas.2018.06.001
Azyabi, N.G., 2018. The Influence of knowledge management on e-business adoption in Saudi SMEs. Int. J. Information Knowledge Manage., 8: 23-94. DOI: 10.1080/02681 102.2017.1390437

Baabdullah, A.M., A.A. Alalwan, N.P. Rana. H. Kizgin and P. Patil, 2019. Consumer use of mobile banking in Saudi Arabia: Towards integrated model. Int. J. Information Manage., 44: 38-52. DOI: $10.1016 /$ j.ijinfomgt.2018.09.002

Bart, Y., V. Shankar, F. Sultan and G.L. Urban, 2005. Are the drivers and role of online trust the same for all web sites and consumers? A large-scale exploratory empirical study. J. mark., 69: 133-52. DOI: $10.1509 /$ jmkg.2005.69.4.133

Brown, J. and H.N. 0, 2018. Usability of Alzheimer's mhealth applications. J. Best Practices Health Professions Diversity: Educ. Res. Policy, 1: 11. DOI: $10.1177 / 1541931218621115$

Chaffey, D., 2015. Digital business and e-commerce management. Pearson Education Limited.

Chin, W., A. Kurowski, G. Chen, R. Gore and L. Punnett, 2018. Enhancing the usability of a mobile app for process evaluation in a participatory ergonomics healthcare intervention. Proceedings of the Congress of the International Ergonomics Association, (IEA'18), Springer, Cham, pp: 523-530. DOI: 10.1007/978-3-319-96071-5_56

Chong, S. and R. Law, 2018. Review of studies on airline website evaluation. J. Travel Tourism Mark., 36: 60-75.

DOI: $10.1080 / 10548408.2018 .1494084$

Danielson, C.K., J.L. McCauley, K.S. Gros and A.M. Jonesand, S. Barr, 2014. SiHLE Web. com: Development and usability testing of an evidencebased HIV prevention website for female AfricanAmerican adolescents. Health Informatics J., 22: 194-208. DOI: 10.1177/1460458214544048

Durucu, M., M. Isik and F.Calisir, 2019. What is more important to internet banking website users: usability or functionality? Int. J. Business Inform. Syst., 30: 232-251.DOI: 10.1504/IJBIS.2019.10018677

ECSA, 2018. E-Commerce in Saudi Arabia. http://www.citc.gov.sa/en/reportsandstudies/Reports /Documents/CITC_ECOMMERCE_2017_ENGLIS H.PDF

Fleming, J. and R. Koman, 1998. Web navigation: designing the user experience. Sebastopol, CA: O'reilly.

Fung, R.H., D.K. Chiu, E.H. Ko, K.K. Ho and P. Lo, 2016. Heuristic usability evaluation of university of hongkong libraries' mobile website. J. Academic Librarianship, 42: 581-94. DOI: 10.1016/j.acalib.2016.06.004 
Gerber, S.M., R.M. Müri, U.P. Mosimann. T. Nef and P. Urwyler, 2018. Virtual reality for activities of daily living training in Neurorehabilitation: A usability and feasibility study in healthy participants. Proceedings of the 40th Annual International Conference of the IEEE Engineering Medicine Biology Society, IEEE, pp: 1-4.

Hasbullah, N.A., A. Osman, S, Abdullah S.N, Salahuddin and N.F. Ramlee et al., 2016. The relationship of attitude, subjective norm and website usability on consumer intention to purchase online: An evidence of Malaysian youth. Procedia Econ. Finance, 35: 493-502.

DOI: 10.1016/S2212-5671(16)00061-7

Heiman, T., C.S. Fichten, D. Olenik-Shemesh and N.S. Keshet, M. Jorgensen, 2017. Access and perceived ICT usability among students with disabilities attending higher education institutions. Educ. Inform. Technol., 22: 2727-40.

DOI: $10.1007 / \mathrm{s} 10639-017-9623-0$

Hidayat-ur-Rehman, I., S.A. Mokhtar and H. Katan, 2016. An empirical analysis of cosnsumers' continuance intention towards online shopping. Mediterranean J. Social Sci., 6: 7-95.

DOI: $10.5901 /$ mjss. 2016.v7n5p95

https://garyperlman.com/quest/

Kim, S. and Y. Lee, 2006. Global online marketplace: A cross-cultural comparison of website quality. Int. J. Consumer Studies, 30: 533-543. DOI: $10.1111 / \mathrm{j} .1470-6431.2006 .00522 . \mathrm{x}$

Monk, A., 2000. User-Centred Design. In: Home Informatics and Telematics: Information, Technology and Society, Sloane, A. and F. van Rijn (Eds.), Springer, Boston, MA, ISBN-10: 0792378679, pp: 181-190.

Nantel, J. and E. Glaser, 2008. The impact of language and culture on perceived website usability. J. Eng. Technol. Manage., 25:112-22.

DOI: 10.1016/j.jengtecman.2008.01.005

Nielsen, J., 1999. Designing web usability: The practice of simplicity. New Riders Publishing.

Pee, L.G., J. Jiang, G. Klein, 2018. Signaling effect of website usability on repurchase intention. Int. J. Information Manage., 39: 228-41. DOI: 10.1016/j.ijinfomgt.2017.12.010

Pipek. V. and V. Wulf, 2009. Infrastructuring: Toward an integrated perspective on the design and use of information technology. J. Association Inform. Syst., 10: 1. DOI: 10.17705/1jais.00195

Rehman, A., 2016. Cultural Usability in E-commerce Website Design: Using Objective Characteristics. J. Applied Emerging Sci., 7: 183-189.

DOI: $10.1016 /$ j.csi.2016.09.013
Saeed, S. and A. Amjad, 2013. Understanding usability issues of Pakistani university websites. Life Sci. J., 10: 479-482. DOI: 10.1007/978-3-319-05963-1_11

Saeed, S. and S. Shabbir, 2014. Website usability analysis of non rofit organizations: A case study of Pakistan. Int. J. Public Administration Digital. Age., 1: 70-83

Saeed, S. I. Jamshaid and S.S. Ikander, 2012. Usability evaluation of hospital websites in Pakistan. Int. J. Technol. Diffusion, 3: 29-35. DOI: $10.4018 /$ jtd.2012100103

Saeed, S., 2019a. Digital business adoption and customer segmentation: An Exploratory Study of Expatriate Community in Saudi Arabia, ICIC Express Letters.

Saeed, S., 2019b. Website usability evaluation of nonprofit organizations: An exploratory study of Saudi Arabia. J. Computer Sci., 15: 346-356. DOI: $10.3844 /$ jcssp.2019.346.356

Saeed, S.F. Wahab, S.A, Cheema and S. Ashraf, 2013. Role of usability in E-government and E-commerce Portals: An Empirical Study of Pakistan. Life Sci. J., 10: 484-489.

SANB, 2018. Saudi Arabia is next battleground for ecommerce titans Arab News. http://www.arabnews.com/node/1305356/businesseconomy

Santa, R., J.B. MacDonald and M. Ferrer, 2018. The role of trust in e-Government effectiveness, operational effectiveness and user satisfaction: Lessons from Saudi Arabia in e-G2B. Government Information Quarterly.

Schuler, D. and A. Namioka, 1993. Participatory Design: Principles and Practices. 1st Edn., CRC Press, ISBN-10: 0805809511, pp: 334.

Sfernrianto, I.O., A. Christiani and M.P. Mulani, 2018. Impact of E-services in customer loyalty in marketplace in Indonesia. J. Theoretical Applied Information Technol., 96: 125-132.

DOI: $10.21512 /$ bbr.v9i2.4650

Solomon, P.N., 2017. Technological usability and effectiveness of the E-Learning system: Evidence from muni university, Uganda. Eur. J., Open Education E-Learning Studies, 2:24.2501-9120

UNCTAD B2C E-COMMERCE INDEX, 2017. https://unctad.org/en/PublicationsLibrary/tn_unctad ict4d09_en.pdf

Valenti, A.M., 2018. Usability testing for a community college library website. Library Hi Tech News, 36 :1-8. DOI: 10.1108/LHTN-06-2018-0039

Wulf, V., C. Müller. V. Pipek, D. Randall and M. Rohde et al., 2015. Practice-Based Computing: Empirically Grounded Conceptualizations Derived from Design Case Studies. In: Designing Socially Embedded Technologies in the Real-World, Wulf, V., K. Schmidt and D. Randall (Eds.), Springer, London, ISBN-30: 978-1-4471-6720-4 pp: 111-150 
Xu, G., A. Cockburn and B. McKenzie, 2001. Lost on the Web: An introduction to Web navigation research. Proceedings of the 4th New Zealand Computer Science Research Students Conference, (RSC' 01).
Zaphiris, P. and S. Kurniawan, 2007. Human computer interaction research in web design and evaluation. IGI Global. 